\title{
Correction to: Identification of passion fruit (Passiflora edulis) chromosomes using BAC-FISH
}

\author{
M. A. Sader (D) - Y. Dias • Z. P. Costa • C. Munhoz • H. \\ Penha $\cdot$ H. Bergès $\cdot$ M. L. C. Vieira $($ iD $\cdot$ A. \\ Pedrosa-Harand $(\mathbb{D}$
}

Published online: 19 May 2020

(C) Springer Nature B.V. 2020

\section{Correction to: Chromosome Res (2019) 27:299-311 https://doi.org/10.1007/s10577-019-09614-0}

The article "Identification of passion fruit (Passiflora edulis) chromosomes using BAC-FISH," written by Mariela A. Sader, Yhanndra Dias, Zirlane P. da Costa, Carla Munhoz, Helen Penha, Hélène Bergès, Maria Lucia C. Vieira, and Andrea Pedrosa-Harand, was originally published with incorrect values in Figure 4. The correct Figure 4 is presented below.

M. A. Sader · Y. Dias · A. Pedrosa-Harand $(\bowtie)$

Departamento de Botânica, Laboratório de Citogenética e Evolução Vegetal, Centro de Biociências, Universidade Federal de Pernambuco, R. Prof. Moraes Rego, s/n, CDU, Recife, PE 50670-901, Brazil

e-mail: andrea.harand@ufpe.br

Z. P. Costa $\cdot$ C. Munhoz - M. L. C. Vieira Department of Genetics, "Luiz de Queiroz" College of Agriculture, University of São Paulo, Piracicaba, Brazil
H. Penha

Department of Technology, Faculty of Agricultural and Veterinary Sciences, São Paulo State University (UNESP), Jaboticabal, Brazil

H. Bergès

French Plant Genomic Resources Center (CNRGV)/INRA, Toulouse, France 




Figure 4 Idiogram of passion fruit showing the relative chromosome size (Chr., in $\mu \mathrm{m}$ and Mbp), centromere positions (ar, arm ratio), rDNA loci (5S and 35S), and single-copy BAC clone positions for six identified chromosome pairs 